JORGE SERRANO

\title{
Acercamiento a la comparación en Aristóteles*
}

\section{Introducción}

T O nos cabe la menor duda acerca del inicio o invención 1 de la metáfora o comparación. Es decir, sabemos perfectamente que Aristóteles no inventó la comparación. Muchos pueblos la utilizaron antes que el Estagirita. La Biblia, por cjemplo, está llena de innumerables comparaciones y metáforas. Incluso tengo la impresión de que toda La Biblia es una gigantesca metáfora a través de la cual se entienden muchas cosas que no aparecen literalmente en ella.

Lo que sí encontramos en Aristóteles es un manejo sistemático de la comparación o metáfora. De igual manera encontramos en el filósofo griego un estudio pormenorizado de la metáfora: sus alcances, sus límites, su validez pedagógica, los diversos niveles que cubre, etcétera.

En nuestros días Paul Ricoeur -entre otros- ha llamado fuertemente la atención sobre la metáfora y su importancia; diversas obras evidencian lo que acabo de señalar. Pero volvdmos a Aristóteles. Fundador de varias ciencias, Aristóteles se dio a la tarea de estudiar el lenguaje - las Categorías, De la interpretación, la Retórica y la Poética, algunas de sus obras- están allí para hacérnoslo ver. Ciertamente su estudio del lenguaje es muy primitivo, sobre todo si lo comparamos con la manera en

* Poncencia prescentada el 15 de diciembre en el II Congreso Nacional de Filosolia que se llevó a cabo en la ciudad de Guadalajara, Jalisco, del 9 al 16 de diciembre de 198.5. 
que actualmente se estudia el lenguaje, ya sea el formal o el ordinario.

Sabía el Estagirita que las cosas tienen un nombre y que con esos nombres de las cosas y otras palabras podemos construir un lenguaje que nos permita entendernos. Así pues, las expresiones que empleamos traducen nuestros pensamientos. En este sentido se dice que hablamos porque pensamos.

Sabemos -y también lo sabía Aristóteles- que existen situaciones o momentos en la vida del ser humano en los que las palabras que empleamos habitualmente se nos revelan súbitamente con su radical insuficiencia. Por una parte son como gritos afónicos venidos a menos, incapaces de expresar el f'uror, el júbilo, la admiración o la desesperación de nuestro ser. $\mathrm{Y}$, por otra parte, son tan bastas, tan primitivas y groseras que parecen incapaces de llegar a perfilar con mediana exactitud un pensamiento, de distinguir entre dos sentimientos, de formular todos los matices del hastío humano.

Sabemos que al ser traducido a palabras, todo pensamiento se enfría, se empobrece. Conviene advertir que esta degradación va precedida de otra; se convierte en pensamiento, lo que en principio era intuición o vivencia, en el momento en que éstas fucron conceptualizadas. Desgraciadamente, parece que el pensamiento posee ya la estructura reductora del lenguaje. Observamos cómo una vivencia amorosa es siempre más rica que cualquier especulación sobre el amor; cómo la sensación de culpa que a veces nos sobrecoge, es mucho más profunda que cualquier pensamiento acerca de nuestra responsabilidad; cómo los sentimientos de gratitud o de gozo que embargan a un sujeto que se sabe amado, son superiores a sus propias ideas en torno a lo que denominamos la felicidad del ser humano. Ahora bien, todas estas ideas y pensamientos habrán de sufrir una nueva y mayor restricción cuando se conviertan -o será mejor decir: se reduzcan a- en palabras. Hay como una depauperación progresiva y fatal.

Cada uno, claro está, percibe mejor aquella deficiencia del lenguaje que más contraria sus pretensiones. Los enamorados se lamentan de que las palabras les resultan insuficientes para declarar su pasión; protestan contra el lenguaje tan átono, uniforme e impersonal. El filósofo lo encuentra demasiado 
* equívoco y concreto. Al poeta, en cambio, quiza le parezca demasiado abstracto, inflexible y pálido. El científico lo quiere más riguroso; el sofista, más ambiguo, El pedagogo echa de menos un lenguaje más claro, aunque el místico preferiría otro más obcuro. Nunca -según parece- podrá darse una coincidencia perfecta entre la experiencia, que es personal y concreta, y sus signos lingüísticos, que son universales y abstractos.

Consciente de todo esto $-y$ de algo más que se podría añadir-Aristóteles echó mano -entre otras cosas y como recurso para su filosofía- y sometió a estudio la metáfora, la comparación para ser empleada como vehículo menos inadecuado en cuanto transmisor de conocimientos, como pedagogía académica y como criterio crítico del discurso filosófico.

\section{La comparación en Aristóteles}

La presente ponencia pretende ser una aproximación o introducción al estudio de la comparación en Aristóteles. De ninguna manera pretende ser exhaustiva y completa. El tema, además de importante, es muy amplio. Los límites de la ponencia no permiten sino hacer una introducción al tema, además de señalar sus principales ideas.

Es instructiva la no equivalencia - buscada voluntariamente- entre comparación y metáfora en el caso de Aristóteles en particular. En efecto, podemos pensar -como primera aproximación- en una cita doctrinal del mismo Aristóteles. Esta se refiere de hecho a la metáfora y no precisamente a la comparación. Sin embargo, si continuamos investigando en el corpus aristotelicum encontramos que la metáfora puede servir como comparación y viceversa, ya que sólo cambia la formulación: "la comparación (en algunas traducciones aparece el término 'imagen' en lugar del término comparación) también es metáfora, ya que difiere poco de ella". ${ }^{1}$

Al tratar de las propiedades de la expresión, y en primer lugar de la claridad, Aristóteles dice que los términos propios dan claridad al lenguaje, mientras que los traslaticios lo elevan

1 Aristóteles, Retórica, 1406b, 14-17. Todas las citas de Aristóteles han sido tomadas del libro Obras de Aristóteles, $2^{\text {a }}$ edición, traducción de Francisco P. Samaranch, Madrid, Editorial Aguilar, 1967. 
y le prestan ornamento. A continuación puntualiza particularmente sobre la metáfora y señala que "La metáfora, más que nada es la que da claridad y agrado y distinción". ${ }^{2}$

Téngase presente que se trata, desde luego, de la metáfora adecuada, como lo precisa Aristóteles. De cualquier manera no deja de llamar la atención que el mismo Aristóteles atribuya a la metáfora la primacía en el orden de la claridad. La metáfora será adecuada -agrega- si tiene su base en la debida proporción; de lo contrario, se mostrará que es impropia, pues las notas divergentes se encuentran sobre todo en la yuxtaposición.

De esto se puede inferir que también las notas convergentes y semejantes destacarán sobre todo en la yuxtaposición, dado el caso que tuviéramos la metáfora apropiada, fundada -de nuevo- en la debida proporción. Y esto ha de ser, evidentemente, en beneficio de la claridad, de esa claridad que Aristóteles ha adjudicado a la metáfora, sobre toda otra forma de expresión.

Si se transfieren ahora estas conclusiones de la metáíora a la comparación, cuando menos dentro del ámbito de la teoría y de la práctica del mismo Aristóteles, que tan íntimamente vincula una a otra, se puede concluir que es también la claridad lo que en primer lugar pide a la comparación la especulación aristotélica, tan conocida por su carácter abstracto.

Aristóteles ha vinculado la claridad a la metáfora más que a ningún otro recurso expresivo; claridad que haremos extensiva - de manera hipotética, pero no gratuita- a la comparación.

Ahora bien, esta claridad ha sido rebajada por muchos comentaristas a recurso de iluminación extrínseca del pensamiento, o también a simple ornato o a los demás valores estético-literarios tan bien registrados por Aristóteles. Téngase presente que Aristóteles no postula el atributo de la claridad sino para la metáfora apropiada, fundada en la semejanza. En esa claridad confiamos al acercarnos al binomio comparación y pensamiento en Aristóteles.

La icomparación es una figura del lenguaje, aunque en

\footnotetext{
2 Aristótcles, Retórica, 1405a, 8-9.
} 
este caso sin implicación literaria alguna. Se puede describir como aquello que vincula dos términos explícitos mediante una conexión gramatical que indica semejanza. ${ }^{3}$ Jamás debe confundirse la comparación con el ejemplo, simple verificación de la noción o ley general en un caso concreto. El ejemplo carece casi siempre de aquella alteridad en los términos que es indispensable para lograr la yuxtaposición, gracias a la cual destacan, según el parecer de Aristóteles, las notas divergentes y, por lo mismo, como ya se dijo, las convergentes y semejantes.

Queremos aquí mostrar que la comparación, como la entiende Aristóteles -en cuanto forma de pensamiento- permite ser desdoblada en dos vertientes esenciales: la que está frente al sujeto cognoscente y la que mira a los objetos implicados; el que trata de conocer y la comparación misma. La primera atañe a la comparación en cuanto función cognoscente; la segun$\mathrm{da}$, a la validez cognoscitiva de la función. La primera es gnoseológica; la segunda, viene a ser crítico-ontológica.

La obra de Aristóteles, valiosa por muchos conceptos, no sólo considera las comparaciones como una forma práctica de pensamiento, sino que además formula una teoría de la comparación, la cual, evidentemente, nos interesa para la interpretación de sus comparaciones.

Hace ya tiempo que Paul Ricoeur llamó la atención de manera sistemática e insistente, sobre la importancia de la metáfora en el discurso. En una de sus obras se pregunta: ${ }^{4}$ " $\mathrm{c}$ s la metáfora una obra en miniatura? La obra completa, ¿ puede ser considerada como una metáfora prolongada?" A estas cuestiones viene a dar una respuesta sustancialmente afirmativa. Existe, según P. Ricoeur, una cierta convergencia entre la interpretación de la metáfora y la de la obra de que ella forma parte. Así, si la interpretación de metáforas locales es iluminada por la interpretación del texto como un todo, también viceversa: "la interpretación de la obra, tomada como un todo, es

\footnotetext{
3 Puede tratarse de conjunción, ad verbio, adjetivo o expresión equivalente.

4 Ricoeur, P., "La métaphore et le probleme central de l'herméneutique", en Revue Philosophique de Louvain, 70, Février, 1972, pp. 93-112.
} 
controlada por la explicación de la metáfora como fenómeno local del texto". 5

Ahora bien, es notable que el ejemplo que cita Ricoeur procede curiosamente de la Poética de Aristóteles. En realidad este ejemplo le permite a Ricoeur mostrar la doctrina de la metáfora y de la mimesis, entre las cuales ve la presunta conexión de la tesis que intenta formular. Veamos esto con algún detenimiento. Señala Aristóteles que la mimesis hace parecer las acciones humanas más altas de lo que son en realidad; por otro lado, la función de la metáfora es trasponer los significados del lenguaje ordinario en favor de los peregrinos. Se pregunta $\mathrm{Ri}$ cocur si no existe una afinidad profunda al mismo tiempo que mutua entre el proyecto de hacer parecer las acciones humanas mcjores de lo que son y el procedimiento especial de la metáfora que eleva el lenguaje por encima de sí mismo.

No obstante que hay algunas diferencias entre la metáfora y la comparación en la doctrina de Aristóteles, prácticamente se equiparan -como lo aclararé más adelante. Aunque el objetivo que Aristóteles y Ricocur persiguen, y probablemente también la visión que uno y otro profesan, es distinta, no deja de llamar la atención sobre lo similar de ambos proyectos. En efecto, por muy sugestiva que sea la persecución de las imágenes o comparaciones en la esfera del subconsciente, pienso que la alienación de las mismas en el plano de lo consciente es algo quc posec su verdad; más aún, parece que la investigación de esta verdad precede al sondeo del subconsciente.

\section{Cuál es la concepción que Aristóteles tiene de la comparación}

Sobre la significación de la comparación, Aristóteles afirma, primero, que: “...es imposible aprenderla de otro y es indicio de dones naturales, ya que usar bien de la metáfora equivale a percibir lo semejante. ${ }^{6}$

De estar en lo cierto Aristóteles, resulta que es posible, a través del breve recurso de la comparación o la metáfora -por así decirlo: sello individual y obra en miniatura- discernir algún rasgo esencial del pensamiento aristotélico. Existen obras

5 Aprud E.I Martino, Aristóteles. El alma y la comparación, p. 13.

' Aristótcles, Pó́tica, 1459a, 6-8. 
de Aristóteles en las cuales esto sería posible, pero habría otras en las que sería un poco más difícil.

En segundo lugar -y aclarando algo que quedó pendiente- Aristóteles ha vinculado tan íntimamente la comparación a la metáfora, que se puede decir que no trata de la comparación sino para inculcar su reducción a la metáfora, al menos en su contenido conceptual. Veamos algunos pasajes de las obras de Aristóteles en los cuales apoyamos nuestra afirmación:

La comparación es también metáfora puesto que se la diferencia en poco. Así, cuando el poeta dice de Aquiles "se precipitó como un león", es comparación; y, si dice "hechọ un león se precipitó", es metáfora. Por el hecho de que ambos son valientes llama león a Aquiles por traslación. La comparación es útil también en la prosa pero usada pocas veces por ser un tanto poética. Las comparaciones han de usarse como las metáforas puesto que son metáforas que sólo se diferencian en lo dicho. ${ }^{7}$

Añade en otro lugar:

...y en la República de Platón se dice que los que despojan los cadáveres se asemejan a los perros que muerden las piedras pero no tocan al que las lanza... Y Pericles dice de los de Samos que se asemejan a los niños pequeños que lloran mientras aceptan el bocado. Y de los beocios, que son semejantes a las encinas, las cuales son derribadas unas por otras (o por chocar unas con otras en el vendaval al caer, o tal vez porque son cortadas por una hacha que tiene el mango de la misma madera); así también, los beocios por sus luchas internas...8

Tras la lista de comparaciones, Aristóteles insiste, una vez más - tercera vez en este grupo de comparaciones- en la vinculación entre metáfora y comparación. Veamos:

Así, pues, todas estas expresiones pueden usarse ya como compáraciones, ya como metáforas, de suerte que cuantas son aprobadas como metáforas, servirán también evidentemente como comparaciones, así como las comparaciones son metáforas carentes de formulación. Pero siempre la metáfora proporcional ha de poder aplicarse recíprocamente a cada uno de los

7 Aristóteles, Retórica, 1406b, 20-26.

8 Ibid. 
términos homogéneos; por ejemplo, si la copa es el escudo de Dionisio, también puede llamarse al escudo copa de Ares. ${ }^{9}$

Pero es preciso que aclaremos y amplifiquemos lo que Aristóteles nos dice acerca de lo "proporcional" en la metáfora, ya que parece, por su insistencia, que esto es medular en el recurso de las metáforas. Tal parece que cuando Aristóteles trata de la metáfora estuviera pensando particularmente en la metáfora proporcional:

El aprender con facilidad es agradable a todos por naturaleza, $\mathrm{y}$, como las palabras significan algo, aquéllas que nos proporcionan enseñanza son las más-agradables. Las palabras extrañas no las comprendemos, y ya conocemos las palabras propias. La metáfora es la que sobre todo produce aquel efecto, pues cuando Homero llama paja a la vejez nos enseña e informa por medio del género; porque las dos se han marchitado. También las comparaciones de los poetas producen el mismo efecto; por lo que, si son propias, causan impresión de elegancia. Pues la comparación, como hemos dicho anteriormente es una metáfora que se distingue por una adición; por eso no es tan grata, por ser más larga. Y tampoco dice que esto es aquello; por lo cual tampoco el alma examina esto. ${ }^{10}$

Vemos, pues, que Aristóteles asimila comparación y metáfora por su contenido conceptual. Queremos hacer aquí dos añadidos. Aristóteles se refiere en todos estos casos -y en muchos otros también- a la metáfora "proporcional". Nos quedan, pues, dos cuestiones pendientes: qué es metáfora, y qué es lo "proporcional" en una metáfora.

Por lo que puede observarse, Aristóteles asimila la comparación a la metáfora; esto ya quedó claro. Veamos ahora lo que entiende por metáfora, ya que a ésta ha sido reducida la comparación. Aunque no sólo en la Poética aparece lo que el de Estagira entiende por metáfora, ahí encontramos la siguiente cita: "Metáfora es la traslación de un nombre ajeno, sea del género a la especie, de la especie al género, de la especie a la especie, o según lo proporcional". 11

\footnotetext{
${ }^{9}$ Aristóteles, Retórica, 1407a, 1-5.

10 Aristóteles, Retórica, 1410b, 10-19.

${ }^{11}$ Aristóteles, Poética, 1457b, 6-9.
} 
Y agrega:

Llamo proporcional cuando el segundo término es al primero semejantemente a como el cuarto es al tercero. Porque entonces dirán el cuarto en lugar del segundo, o el segundo en lugar del cuarto... Hablando en ejemplos, la copa es para Dionisio así como el escudo es para Ares. Y la vejez es a la vida lo que la tarde al día; se llamará, por lo tanto a la tarde vejez del día, y a la vejez la tarde de la vida, como hace Empédocles, u ocaso de la vida. ${ }^{12}$

Aristóteles destaca, entre todas las clases de metáfora, la que es "proporcional". A fin de cuentas ésta parece encarnar, strictu sensu, a la metáfora, ya que la primera y la segunda más bien se refieren a sinécdoques. La tercera se refiere a la metáfora "proporcional".

De las cuatro clases de metáfora las más aceptadas son las que se basan en la proporción. Así Pericles dijo de la juventud que había desaparecido de la ciudad como si alguien hubiese arrebatado al año la primavera. Y Leptines hablando de los lacedemonios, dijo que no se podía permitir el que se mirase con indiferencia cómo Grecia había sido privada de un ojo. ${ }^{13}$

La metáfora es, pues, una "proporción". Aunque ciertamente no se trata de una "proporción" matemática - en todo caso no es estrictamente lo que el matemático entiende por "proporción". Más bien sería algo semejante a lo que Aristóteles entiende -en otra de sus obras-como la definición de la justicia; allí señala Aristóteles: "Lo justo es lo proporcional. Porque lo proporcional no es únicamente propio del número, sino en general, de la cuantidad. Pues la proporción es la igualdad de dos relaciones y consta al menos de cuatro términos". ${ }^{14}$

Los traductores de las obras de Aristóteles nos señalan -v. gr., Martino en su obra citada- que no quisieron traducir al castellano "igualdad de dos razones" con el objeto de escapar a la igualdad matemática, estricta, justamente la que Aristóteles trasciende al aplicar la "proporción" a la justicia.

12 Aristóteles, Poética, 1457b, 16-25.

13 Aristóteles, Retórica, 14 10b, 36-1411a, 5.

14 Aristóteles, Etica nicomaquea, 1131a, 29-32. 
Nótese, igualmente, que al hacer esto Aristóteles en el caso de la comparación o de la metáfora evade la igualdad matemática, relajando, en beneficio de una "proporción" cuyo contenido no es en absoluto cuantitativo, sino simplemente de una semejanza.

La semejanza, como la razón de ser de la comparación o metáfora, se inculca estrictamente en el siguiente pasaje, que es interesante además por otros conceptos que aquí sólo apuntaremos de pasada. Nos parece oportuno citar aquí el siguiente pasaje de Aristóteles porque, justamente basándose en este texto -y otros más del Estagirita- algunos comentadores señalan que la metáfora sólc tiene un papel estilístico y oratorio. Veamos:

Algunas cosas se expresan no por homonimia ni por metáfora, ni por término propio como, por ejemplo, si se define la ley como medida o imagen de las cosas que son justas por naturaleza. Semejantes expresiones son peores que la metáfora. Porque la metáfora da a conocer de algún modo, mediante la semejanza, lo significado, pues todos los que se valen de la metáfora lo hacen conforme a cierta semejanza. Pero esta expresión no da a conocer pues ni siquiera existe la semejanza conforme a la cual la ley pueda ser medida o imagen ni tampoco se acostumbra a llamarla así en propiedad. De modo que, si alguien dice que la ley es en propiedad medida o imagen, miente. Porque sólo es imagen aquélla que se produce por imitación, lo cúal no ocurre con la ley. Pues, si no habla con propiedad es evidente que habla obscuramente y peor que todas las expresiones que se hacen según metáfora. ${ }^{15}$

No hay que olvidar - para comprender esta disminución de la metáfora-que se trata de salvar o establecer con rigor su definición. Sigue siendo válida, en Aristóteles, la exigencia de semejanza que él mismo formula para la comparación o metáfora.

Pero, finalmente, ¿qué es lo que significa propiamente la semejanza en Aristóteles? Todo el problema de la metáfora y de la comparación estriba en esto. So pena de tener que eliminar todo lo anterior, tenemos que llegar a precisar, ponderar y

15 Aristóteles, Tópicos, 140a, 6-17. 
aceptar -o no- la validez, tanto de la metáfora como de la comparación que - si hemos entendido a Aristóteles en este punto-descansan en la semejanza. Pensamos que no se trata de un problema sencillo, sino urgente.

En otra obra mayor Aristóteles ${ }^{16}$ había señalado que: "...el ser se dice de muchas maneras"."17

Ahora bien, después de enumerar una serie de esas maneras múltiples del ser, lo mismo afirma Aristóteles de algo que vendría a ser como un correlativo del ser, la semejanza, pues más adelante añade: "...lo semejante se dice de muchas maneras". ${ }^{18}$

Parecería que Aristóteles simplemente ha eludido el problema; lo mismo que ha dicho para el concepto de ser lo afirma para un correlativo: la semejanza. Sin embargo, Aristóteles ha intentado definir lo semejante. Es más, lo intenta varias veces, aunque quizá no satisfecho del todo con las primeras definiciones que propone: "...son semejantes aquellas cosas cuya cualidad es una". 19

Volvemos a encontrarnos con otra definición comprendida dentro de una enumeración de cosas que son semejantes: las que siempre o las más de las veces poseen las mismas afecciones según el filósofo griego: "Aquéllas cuya cualidad es una, las que en común poseen más cualidades contrarias o más importantes". ${ }^{20}$

En otro pasaje de la misma obra, en la cual hace otra enumeración, Aristóteles reitera de varios modos la pertenencia a la misma especie como razón de ser de la semejanza, aun cuando, por otro lado, los ejemplos señalados - nos parececaen bajo la unicidad de la cualidad común, que se ha visto en anteriores definiciones o descripciones de lo semejante: "Por ejemplo, el estaño es semejante a la plata en lo blanco, y el oro al fuego en lo amarillo y rojizo". 21

Después de todo lo anterior podemos concluir lo siguien-

\footnotetext{
16 Aristótcles, Metafísica.

17 Aristoteles, Metafísica, L. IV, Cap. 2, 1003 b.

18 Aristótcles, Metafísica. 1054b, 14.

19 Aristóteles, Metafísica, 1021a, 11-12.

20 Aristóceles, .Metafísica, 1018a, 15-18.

2 Aristóteles, Metafísica, 1054b, 11-12.
} 
țe: la semejanza viene a ser el contenido conceptual de la comparación, contenido del cual arranca -o en el que gravita, depende el ángulo desde el cual observemos- todo lo demás. Y esto porque de la semejanza entre el objeto de la comparación y el objeto comparado arranca la acción que tiende a conocer a este último; i. e.: la función propia de la comparación, como forma de pensamiento. Así como también la validez crítica de la comparación descansará, obviamente, en la pretendida semejanza que ella formula.

\section{Finalidades de la comparación en Aristóteles}

Varias son las finalidades que Aristóteles se propone con las metáforas -o comparaciones-que emplea a lo largo de sus escritos. En primer lugar trata de enseñar algo al que no sabe; o enseñar mejor al que ya sabe. En una palabra, la metáfora o comparación pretenden cumplir una función pedagógica:

El aprender con facilidad es agradable a todos por naturaleza, y, como las palabras significan algo, aquéllas que nos proporcionan enseñanza son las más agradables. Las palabras extrañas no las comprendemos, y ya conocemos las palabras propias. La metáfora es la que sobre todo produce aquel efecto pues, cuando Homero llama paja a la vejez nos enseña e informa por medio del género; porque las dos se han marchitado. También las comparaciones de los poetas producen el mismo efecto. ${ }^{22}$

Si se observa con cuidado este texto de Aristóteles, se puede concluir que lo que realmente enseña es la metáfora. En efecto, las palabras conocidas ya no nos enseñan nada y las desconocidas, por razones diferentes, tampoco. Esto nos muestra -como ya se ha podido observar- la predilección de Aristóteles por lo isomorfo o análogo sobre lo unívoco, en filosofía.

Todo esto tiene gran congruencia con el pensamiento general de Aristóteles. Sabemos, en efecto, que en el Organon dice que existen "cosas más cercanas a nosotros" y que en este sentido son mejor conocidas para nosotros. Existen, por otra parte, objetos que siendo más cognoscibles en sí mismos, lo son

22 Aristóteles, Retórica, 1410b, 10-16. 
menos para nosotros. La demostración, la ciencia, la enseñanza del maestro consiste en llevar al alumno de lo que es más conocido "para nosotros" a lo que es más conocido "por sí o en sí mismo". Esta trayectoria la realiza también la metáfora. La comparación, bien manejada ciertamente, permite que nuestra inteligencia pase de lo sensible a lo inteligible, lo cual es otra manera de expresar lo que ya se ha señalado.

Otro de los objetivos o finalidades que Aristóteles se propone cuando emplea -o cuando enseña el papel de- la metáfora es aprovechar que ésta -o la comparación-posee una validez crítica o gnoseológica. Son múltiples los lugares en donde aparece la explicación de Aristóteles en relación con lo que se viene diciendo. Uno, quizá, de los más lúcidos aparece en su Moral o Etica Nicomaquea. Allí nos hace ver que al tratarse del comportamiento humano las cosas no pueden ser consideradas de manera absoluta; es decir, en el caso del hombre y su comportamiento, las cosas sólo pueden ser aproximadas - como, por otra parte, ocurre con la salud, con la medicina y con la navegación. $Y$, si esto es así, al tratarse de la ética, con mayor razón lo será en cada uno de los casos particulares en los que el mismo sujeto deberá juzgar de la conveniencia -o no-del acto según las circunstancias; así:

En primer lugar hay que tener presente que las cualidades morales son de tal naturaleza que se destruyen por defecto y por exceso, como vemos en las fuerzas y en la salud, pues nos vemos obligados a valernos de testimonios visibles a propósito de las cosas invisibles. Así, los ejercicios excesivos y los deficientes destruyen las fuerzas, y de modo semejante la bebida y la comida perjudican a la salud, si son excesivas o deficientes, mientras que las cantidades adecuadas la producen, la aumentan, la preservan. Así ocurre también con la templanza, el valor y las demás virtudes. ${ }^{23}$

Son varios los elementos que integran el aserto, fundamental para nosotros, de que nos encontramos obligados a valernos de testimonios visibles a propósito o acerca de aquello que es invisible para nosotros. Entre estos elementos se en-

2s Aristotcles, Etica nicomaquea, $1103 \mathrm{~b}$. 
cuentran, por un lado, los testimonios visibles, la necesidad violenta, en ocasiones, que tenemos para recurrir a ellos y las cosas invisibles o, en todo caso, no aparentes, no manifiestas.

Ahora bien, esta necesidad del medio sensible pertenece a la dimensión crítica de la metáfora. Aparece un cariz que estaba ausente en el elemento anterior. En efecto, aquí se trata de un sentido objetivo-subjetivo y no meramente subjetivo como se destacó renglones arriba. Así, vemos que la metáfora remite, conduce al sujeto que está conociendo hacia el objeto invisible -hacia lo inteligible-que es la meta del conocimiento.

Convine destacar aquí que no puede reducirse esta consideración a la función pedagógica, como más de alguna vez se ha pensado. En efecto, en esta segunda función la metáfora no sólo ilumina al sujeto en relación con un objeto invisible -lunción pedagógica- sino que, además, la metáfora constituye un testimonio objetivo, una cierta prueba de que el objeto invisible, el objete inteligible es, en realidad, tal y como se le presenta, a través de la analogía con el objeto visible.

En este sentido, podemos decir que la analogía -en la metáfora o comparación- no viene solamente a iluminar sino que se constituye en la razón de la realidad que analoga.

Esta concepción que Aristóteles tiene acerca de la metáfora lo lleva, incluso, a formulaciones prima facie sumamente audaces. En efecto, en Aristóteles encontramos que este dar testimonio tiene un doble carácter crítico-ontológico:

Si damos fe a lo que observamos en los objetos a nuestro alcance, podemos deducir que la naturaleza de la substancia primera es etcrna e inmutable. Pues parece que el logos da testimonio a los fenómenos, y los fenómenos al logos. ${ }^{24}$

En todos los textos que se han mencionado y en sus comentarios aparece la idea de Aristóteles acerca de la realidad; en efecto, para el filósofo griego la realidad no es "unidimensional", tiene varios niveles, no todo se encuentra en la superficie, ni tamporo todo se encuentra en las profundidades. Esto hace, entre otras cosas, que la realidad, en ocasiones nos sea

24 Aristoteles, Del cielo, 270b, 4-5. 
difícil de alcanzar; mejor dicho, su verdad no nos es tan fácilmente alcanzable. La dificultad de hacerlo resulta doble: "Porque, así como se comportan los ojos de los murciélagos para con la luz del día, así también el entendimiento de nuestra alma para con las cosas más claras por naturaleza" 25

En otro lugar se refiere a lo mismo aunque procede en sentido inverso: "El demostrar las cosas claras por làs obscuras es propio del que no sabe discernir lo que es conocído por sí y lo que no lo es". ${ }^{26}$

De este esbozo o ensayo acerca de la naturaleza y la función que la comparación tiene dentro de la concepción de Aristóteles, podemos extraer conclusiones que permitan tener una noción clara de las ideas que aquí se han expuesto.

\section{Conclusiones}

$1^{\text {a }}$. Aristóteles está convencido de que la realidad tiene una diversa densidad. Existen niveles de profundidad mayor y niveles más superficiales. En este sentido se expresa de manera clara señalando que existe el conocimiento de lo sensible y el conocimiento de lo inteligible.

$2^{2}$. En el tratamiento que Aristóteles hace de la comparación se aprecia una gran congruencia con una de sus más queridas tesis: su forma de concebir el conocimiento. En efecto, Aristótcles señala que nada existe en la inteligencia -en el alma- que antes no hubiera pasado por los sentidos. La comparación viene a ser como un puente entre lo sensible -sentidosy lo inteligible -el alma.

Apoyo lo anterior con la siguiente cita de Aristóteles:

... y como la facultad sensible se relaciona con los sensibles, de modo semejante, el entendimiento debe relacionarse con los inteligibles. Por tanto, es necesario que sea libre de toda mezcla para que conozca; porque si mostrase alguna forma propia juntamente con la extraña, aquélla se opondría a ésta y la interceptaria. ${ }^{27}$

${ }^{2.5}$ Aristótẹles, Melafísica, 993b, 9-11.

26 Aristótcles, Hisica, 193a, 4-6.

27 Aristitcles, Tratado del alma, 431b, 24-432a, 3. 
$3^{\mathrm{a}}$. Son varias las funciones que Aristóteles le confiere a la comparación. Aquí, fundamentalmente, se ha señalado su función pedagógica y su función crítico-ontológica.

Resumo brevemente el contenido de la presente ponencia con un texto de Aristóteles y un comentario mínimo:

Las cosas anteriores y más conocidas lo son de dos maneras, porque no es lo mismo lo que es anterior por naturaleza, y lo que es anterior para nosotros, ni lo que es más conocido por naturaleza, y lo que es más conocido para nosotros. Llamo, pucs, anteriores y más conocidos para nosotros los objetos más cercanos a la sensación, y anteriores y más conocidos de una manera absoluta a los objetos más alejados -de los sentidos. Y las cosas más alejadas son las más universales mientras que las más cercanas - a la sensación- son las individuales; y se corresponden unas y otras mutuamente. ${ }^{28}$

El tránsito de lo sensible a lo inteligible lo lleva a cabo la comparación. Esta es una de sus funciones.

2* Aristiteles. Alnalíticos posteriores, 71b, 33-72a 5. 